Research Article

\title{
Perspektif Guru Terhadap Pembelajaran Pelajar Remaja
}

\author{
Mohd Razimi Husin', Nurulhuda Md Hassan', Victor Yii Zi Sheng², Alia Syazwani Md \\ Tormiz $^{2}$, Nur Syaiera Amera Zulkapli ${ }^{2}$, Milleny Anak George ${ }^{2}$, Roslina Rosli, ${ }^{2}$ Nur Irzwana \\ Rabiatul Adawiyah Mohammad Hishamuddin ${ }^{2}$, Nor Syafiqah Shaharudin ${ }^{2}$, Chelsea \\ Sovency Adampai ${ }^{2}$
}

${ }^{1}$ Fakulti Pembangunan Manusia, Universiti Pendidikan Sultan Idris. Perak, Malaysia.

${ }^{2}$ Fakulti Sains dan Matematik, Universiti Pendidikan Sultan Idris. Perak, Malaysia.

Article History

Received:

01.03.2021

Revised:

11.04.2021

Accepted:

14.04.2021

*Corresponding Author:

Mohd Razimi Husin

Email:

razimi@fpm.upsi.edu.my

This is an open access article, licensed under: $\mathrm{CC}-\mathrm{BY}-\mathrm{SA}$
Abstract: Kajian ini bertujuan untuk meneroka perspektif guru berkaitan dengan pembelajaran pelajar remaja. Kajian ini menggunakan kaedah temubual yang melibatkan seorang guru yang berpengalaman. Instrumen kajian terdiri daripada protokol temubual dan komputer riba. Hasil kajian mendapati bahawa faktor pelajar, faktor guru, dan faktor persekitaran bilik darjah mempengaruhi pembelajaran pelajar remaja. Di samping itu, hasil kajian turut mendapati sekolah yang menyediakan kemudahan dan prasarana yang kondusif serta memberi pengiktirafan dan penghargaan kepada pelajar dan guru mampu meningkatkan pembelajaran pelajar remaja. Dari segi ciriciri pelajar remaja yang cemerlang, dapatan kajian menunjukkan bahawa pelajar remaja yang cemerlang memiliki kemahiran etika dan kerohanian, serta sahsiah yang positif. Selain itu, dapatan kajian juga menunjukkan bahawa guru mengakui keberkesanan penggunaan teknologi dan pembelajaran abad ke-21 dalam meningkatkan pembelajaran pelajar remaja. Hasil kajian turut mendapati bahawa guru perlu berkolaborasi dengan pelajar dan menjadi contoh kepada pelajar bagi mewujudkan persekitaran pembelajaran yang kondusif bagi pelajar remaja. Implikasi terhadap aspek pembelajaran pelajar remaja dibincangkan berdasarkan dapatan yang diperoleh dalam kajian ini.

Kata Kunci: Pelajar Remaja, Pembelajaran, Pembelajaran Abad ke-21.

Teachers' Perspectives on Teenage Student Learning

Abstract: This study aims to explore teachers' perspectives related to adolescent student learning. This study uses an interview method involving an experienced teacher. The study instruments consisted of interview protocols and laptops. The results of the study found that student factors, teacher factors, and classroom environment factors influence the learning of adolescent students. In addition, the results of the study also found that schools that provide conducive facilities and infrastructure as well as give recognition and appreciation to students and teachers are able to improve the learning of adolescent students. In terms of the characteristics of excellent teenage students, the findings show that excellent teenage students have ethical and spiritual skills, as well as a positive personality. In addition, the findings of the study also show that teachers recognize the effectiveness of the use of technology and 21 st century learning in improving the learning of adolescent students. The results also found that teachers need to collaborate with students and be an example to students to create a conducive learning environment for adolescent students. Implications on the learning aspects of adolescent students are discussed based on the findings obtained in this study.

Keywords: 21 st Century Learning, Learning, Teenage Students. 
Mohd Razimi Husin, Nurulhuda Md Hassan, Victor Yii Zi Sheng, Alia Syazwani Md Tormiz, Nur Syaiera Amera Zulkapli, Milleny Anak George, Roslina Rosli, Nur Irzwana Rabiatul Adawiyah Mohammad Hishamuddin, Nor Syafiqah Shaharudin, Chelsea Sovency Adampai.

Perspektif Guru Terhadap Pembelajaran Pelajar Remaja.

Journal of Humanities and Social Sciences, vol. 3, no. 1, pp. 40-49, April 2021. DOI: 10.36079/lamintang.jhass-0301.211

\section{Pendahuluan}

Pembelajaran merujuk kepada perubahan-perubahan yang berlaku ke atas tingkah laku, pengetahuan, dan kemahiran berfikir disebabkan pengalaman yang dilalui oleh individu [1]. Definisi ini turut disokong oleh Schunk [2] yang mendefinisikan pembelajaran sebagai satu perubahan dalam diri individu yang dipengaruhi oleh pengalaman. Dalam konteks pendidikan, Mayer [3] mendefinisikan pembelajaran sebagai perubahan jangka panjang dalam pengetahuan pelajar yang terhasil daripada pengalaman pelajar tersebut.

Pembelajaran pelajar merupakan aspek yang diberikan perhatian dalam sistem pendidikan di seluruh dunia. Di Malaysia, Falsafah Pendidikan Kebangsaan menyatakan bahawa "Pendidikan di Malaysia adalah suatu usaha berterusan ke arah memperkembangkan lagi potensi individu secara menyeluruh dan bersepadu untuk mewujudkan insan yang seimbang dan harmonis dari segi intelek, rohani, emosi dan jasmani berdasarkan kepercayaan dan kepatuhan kepada Tuhan. Usaha ini adalah bagi melahirkan rakyat Malaysia yang berilmu pengetahuan, berketerampilan, berakhlak mulia, bertanggungjawab dan berkeupayaan mencapai kesejahteraan diri, serta memberi sumbangan terhadap keharmonian dan kemakmuran keluarga, masyarakat dan negara.” Bagi mencapai matlamat tersebut, pelbagai inisiatif telah dan akan diambil oleh kerajaan bagi meningkatkan pembelajaran murid seperti yang dinyatakan dalam Pelan Pembangunan Pendidikan Malaysia 2013-2025 (Pendidikan Prasekolah hingga Lepas Menengah) [4].

Dalam konteks psikologi pendidikan, terdapat dua aliran utama yang memberikan pandangan yang berbeza berkaitan dengan konsep pembelajaran, iaitu aliran behaviorisme dan aliran kognitivisme. Menurut pandangan aliran behaviorisme, pembelajaran berlaku disebabkan oleh rangsangan yang diterima daripada persekitaran. Selain itu, aliran ini juga memberi fokus kepada perubahan tingkahlaku-tingkahlaku yang boleh diperhatikan. Dalam erti kata yang lain, aliran behaviorisme tidak memberi penekanan terhadap proses mental yang mampu mempengaruhi pembelajaran. Hal ini dijelaskan berdasarkan dua teori utama dalam behaviorisme, iaitu teori pelaziman klasik dan teori pelaziman operan. Teori pelaziman klasik menegaskan bahawa pembelajaran berlaku disebabkan penyatuan antara rangsangan dan tindakbalas, manakala teori pelaziman operan berpendapat bahawa pembelajaran berlaku berdasarkan akibat yang diterima setelah seseorang melakukan sesuatu tingkahlaku.

Berbeza dengan aliran behaviorisme, aliran kognitivisme memberi penekanan kepada pengaruh proses-proses mental yang tidak boleh diperhatikan dalam mempengaruhi pembelajaran. Sebagai contoh, aliran kognitif sosial yang diperkenalkan oleh Bandura [5] menekankan interaksi antara faktor individu (kognisi), persekitaran dan dan tingkahlaku dalam mempengaruhi pembelajaran. Pendekatan pemprosesan maklumat pula memberi fokus kepada peranan proses-proses mental seperti perhatian, memori, pemikiran dan proses-proses kognitif yang lain dalam pemprosesan maklumat [6]. Pendekatan konstruktivisme kognitif menekankan pembinaan pengetahuan dan kefahaman berdasarkan pembinaan kognisi dalam diri individu [7], manakala pendekatan konstruktivisme sosial memberi penekanan kepada peranan kolaborasi sosial dalam membina pengetahuan dan kefahaman [8]. Menurut Ashcraft dan Radvansky [9] serta Sternberg [10], penekanan terhadap aspek kognitif telah menjadi asas kepada pelbagai pendekatan pembelajaran pada hari ini.

Remaja merupakan tempoh peralihan dalam jangka hayat manusia yang menghubungkan dua peringkat perkembangan, iaitu antara peringkat kanak-kanak dan peringkat dewasa, yang bermula sekitar usia 10 hingga 12 tahun dan berakhir sekitar usia 18 hingga 21 tahun [11]. Seperti peringkatperingkat perkembangan yang lain, perkembangan remaja turut dipengaruhi oleh faktor semulajadi dan faktor persekitaran dan meliputi aspek biologi, kognitif, dan sosioemosi. Pembelajaran remaja boleh dikaitkan dengan aspek perkembangan kognitif, di mana menurut Piaget [12] bahawa remaja berada di peringkat operasi formal yang mampu berfikir secara abstrak, logik, dan ideal. Perubahan kognitif yang berlaku pada peringkat remaja perlu diberi perhatian dalam usaha memastikan keberkesanan proses pembelajaran yang dilalui oleh pelajar remaja.

Dalam konteks pendidikan, keberkesanan sesuatu pembelajaran sering diukur berdasarkan pencapaian akademik pelajar. Dalam hal ini, tinjauan literatur mendapati bahawa antara faktor-faktor yang mempengaruhi pembelajaran pelajar termasuklah faktor pelajar, faktor guru, faktor sekolah, dan faktor teknologi. Dari segi faktor pelajar, Yusoff et al. [13] menyatakan bahawa pencapaian pelajar dipengaruhi oleh penglibatan mereka dalam proses pembelajaran. Ainun et al. [14] mendapati bahawa pembelajaran abad ke-21 mempengaruhi pencapaian pelajar sekolah menengah dalam matapelajaran Bahasa Melayu. Secara spesifik, ciri-ciri pembelajaran abad ke-21 yang dimaksudkan 
meliputi kemahiran-kemahiran yang perlu dimiliki oleh pelajar iaitu kemahiran komunikasi, kemahiran sains dan teknologi, kemahiran berfikir, kemahiran interpersonal, kemahiran intrapersonal, kemahiran 3M (membaca, mengira dan menulis), dan sebagainya. Abu dan Leong [15] pula mendapati bahawa faktor sikap dan minat pelajar mempengaruhi pencapaian pelajar Tingkatan Empat dalam matapelajaran Matematik Tambahan.

Dari segi faktor guru, tinjauan literatur mendapati bahawa guru perlu memiliki empat kompetensi utama yang meliputi aspek pengetahuan, kemahiran, pengalaman dan sahsiah [16]. Hal ini turut disokong oleh Ahmad dan Jinggan [17] yang menyatakan bahawa antara kompetensi yang perlu dimiliki oleh seseorang guru termasuklah pengetahuan kandungan, pengetahuan pedagogi, keupayaan memilih sumber pengajaran, kemahiran untuk mempelbagaikan strategi pengajaran, kemahiran teknologi, kemahiran komunikasi, serta sikap dan personaliti yang positif seperti bermotivasi, humor dan berkeyakinan. Kenyataan ini turut dikukuhkan oleh hasil kajian yang dijalankan oleh Abu dan Leong [15] yang mendapati peranan signifikan yang dimainkan oleh strategi pengajaran guru dalam mempengaruhi pencapaian pelajar Tingkatan Empat dalam matapelajaran Matematik Tambahan selaindapatan kajian yang dijalankan oleh Ahmad et al. [18] yang mendapati hubungan yang signifikan antara kemahiran mengajar yang dimiliki oleh guru dengan pencapaian murid dalam mata pelajaran Sejarah.

Dari segi faktor sekolah, kajian lepas mendapati bahawa sekolah yang menghormati kepelbagaian yang wujud dalam kalangan pelajar berupaya meningkatkan pembelajaran pelajar [19]. Selain itu, persepsi guru dan pelajar terhadap iklim sekolah juga didapati mempengaruhi pencapaian pelajar [20]. Harinarayanan dan Pazhanivelu [21] mendapati bahawa persekitaran sosial yang positif di sekolah mempunyai hubungan yang positif dengan pencapaian akademik pelajar sekolah menengah. Dalam kajian tersebut, persekitaran sosial yang positif dicirikan sebagai persekitaran yang memberi kebebasan kepada pelajar untuk mengekspresikan minat, kegemaran, dan sikap. Zainuddin dan Subri [22] pula mendapati bahawa sekolah yang menyediakan kemudahan fizikal yang baik dan mencukupi mempengaruhi pembelajaran dan pencapaian pelajar.

Selain faktor pelajar dan guru, tinjauan literatur turut mendapati bahawa penggunaan teknologi maklumat dan komunikasi (ICT) turut mempengaruhi pembelajaran pelajar. Hal ini disebabkan oleh keupayaan ICT dalam meningkatkan tarikan dan keberkesanan proses PdP [23], [24]. Di samping itu, penggunaan ICT dalam proses pengajaran dan pembelajaran juga mampu mewujudkan suasana pembelajaran yang menyeronokkan dan meningkatkan kualiti pengajaran guru [25]. Selain itu, penggunaan ICT juga didapati mempercepat penerimaan murid serta menjana pemikiran murid [26]. Berdasarkan tinjauan literatur yang dijalankan, pihak pentadbir sekolah dan guru disarankan agar menyediakan persekitaran pembelajaran yang menggalakkan pencapaian, kepuasan dan minat remaja [27].

Kajian ini dijalankan bagi meneroka perspektif guru berkaitan dengan pembelajaran pelajar remaja. Secara spesifik, objektif kajian ini adalah untuk meneroka perspektif guru berkaitan aspekaspek berikut:

1. Faktor-faktor yang mempengaruhi pembelajaran pelajar remaja.

2. Ciri-ciri sekolah yang mampu meningkatkan pembelajaran pelajar remaja.

3. Ciri-ciri pelajar remaja yang cemerlang.

4. Cabaran yang dihadapi dalam proses pengajaran dan pembelajaran pelajar remaja.

5. Keberkesanan penggunaan teknologi dalam konteks pembelajaran pelajar remaja.

6. Keberkesanan pembelajaran abad ke-21 dalam meningkatkan keberkesanan pembelajaran pelajar remaja.

7. Peranan guru dalam mewujudkan persekitaran pembelajaran yang kondusif bagi pelajar remaja.

\section{Metodologi Kajian}

Kajian ini menggunakan kaedah temubual yang melibatkan seorang guru yang mempunyai pengalaman mengajar selama 16 tahun. Temubual telah dijalankan melalui aplikasi Google Meet dan telah berlangsung selama sejam. Instrumen kajian terdiri daripada protokol temubual yang terdiri daripada soalan-soalan berkaitan pembelajaran pelajar remaja dan komputer riba bagi merakam sesi temubual yang dijalankan. Beberapa langkah telah diambil sebelum temubual dijalankan seperti 
penyediaan soalan protokol temubual, pemilihan informan, dan penentuan masa dan tarikh untuk menjalankan temubual. Sesi temubual telah dirakam dan verbatim telah disediakan bagi tujuan analisis data bagi mencapai objektif-objektif kajian.

\section{Dapatan Kajian}

Dapatan kajian dibentangkan mengikut objektif-objektif yang cuba dicapai melalui kajian ini.

1. Faktor-faktor yang mempengaruhi pembelajaran pelajar remaja

2. Ciri-ciri sekolah yang mampu meningkatkan pembelajaran pelajar remaja

3. Ciri-ciri pelajar remaja yang cemerlang.

4. Cabaran yang dihadapi dalam proses pengajaran dan pembelajaran pelajar remaja

5. Penggunaan teknologi dalam konteks pembelajaran pelajar remaja

6. Keberkesanan pembelajaran abad ke-21 dalam meningkatkan keberkesanan pembelajaran pelajar remaja

7. Peranan guru dalam mewujudkan persekitaran pembelajaran yang kondusif bagi pembelajaran remaja.

\subsection{Faktor-Faktor Yang Mempengaruhi Pembelajaran Pelajar Remaja}

Berdasarkan dapatan yang diperoleh daripada temubual yang dijalankan, terdapat pelbagai faktor yang mempengaruhi pembelajaran pelajar remaja, di mana faktor-faktor tersebut boleh dikategorikan kepada tiga faktor, iaitu faktor pelajar, faktor guru, dan faktor persekitaran bilik darjah. Dari segi faktor pelajar, informan menyatakan bahawa pelajar remaja perlu bersedia dari segi kognitif dan emosi bagi meningkatkan keberkesanan pembelajaran mereka. Dapatan ini ditunjukkan dalam petikan kata-kata informan seperti berikut:

“...kesediaan pelajar untuk belajar, di manakah tahap mereka untuk ingin menimba ilmu pengetahuan ...". Kesediaan pelajar untuk belajar, emosi pelajar, ini juga kita perlu mengambil berat.

Dari segi faktor guru, dapatan daripada temubual menunjukkan bahawa kompetensi yang dimiliki oleh guru mampu mempengaruhi pembelajaran pelajar remaja, di mana kompetensi tersebut meliputi aspek kemahiran, pengetahuan, dan sahsiah yang dimiliki oleh seseorang guru. Dapatan ini ditunjukkan dalam petikan kata-kata informan seperti berikut:

"Kalau cikgu itu dapat menarik perhatian, dapat menarik hati pelajar, saya rasa itu merupakan salah satu faktor juga ini. Yang kedua adalah pengetahuan dan kompetensi guru. Kalau guru tersebut memang kompeten dengan pengetahuan yang sedia ada rasanya ini memang akan mempengaruhilah pembelajaran pelajar untuk terus maju...guru yang komited dan sentiasa memastikan sesi PdPc adalah yang terbaik."

Selain itu, dapatan kajian turut menunjukkan bahawa faktor persekitaran bilik darjah turut mempengaruhi pembelajaran pelajar remaja. Dalam hal ini, keadaan bilik darjah yang kondusif yang memiliki suasana yang menyeronokkan serta melibatkan kerjasama antara guru dan pelajar dikatakan mampu mempengaruhi pembelajaran pelajar remaja. Dapatan ini ditunjukkan dalam petikan kata-kata informan seperti berikut:

"Keadaan bilik darjah yang kondusif, suasana pembelajaran yang seronok dan aktif.... bekerjasama dengan guru dalam sesi PdPc supaya objektif PdPc dalam kelas tercapai ..."

\subsection{Ciri-Ciri Sekolah Yang Mampu Meningkatkan Pembelajaran Pelajar Remaja}

Berdasarkan dapatan yang diperoleh daripada temubual yang dijalankan, sekolah yang mampu meningkatkan pembelajaran pelajar remaja memiliki ciri-ciri seperti kemudahan dan prasarana yang kondusif serta memberi pengiktirafan dan penghargaan kepada pelajar dan guru. Dapatan ini ditunjukkan dalam petikan kata-kata informan seperti berikut: 
Mohd Razimi Husin, Nurulhuda Md Hassan, Victor Yii Zi Sheng, Alia Syazwani Md Tormiz, Nur Syaiera Amera Zulkapli, Milleny Anak George, Roslina Rosli, Nur Irzwana Rabiatul Adawiyah Mohammad Hishamuddin, Nor Syafiqah Shaharudin, Chelsea Sovency Adampai.

“...kemudahan dan prasarana sekolah yang kondusif melahirkan pelajar seronok ke sekolah...memberi pengiktirafan dan penghargaan kepada pelajar dan juga guru, rasa dihargai dan add on value sense of belonging to the school."

\subsection{Ciri-Ciri Pelajar Remaja Yang Cemerlang}

Berdasarkan dapatan yang diperoleh daripada temubual yang dijalankan, ciri-ciri pelajar remaja yang cemerlang boleh dibahagikan kepada tiga ciri utama, iaitu kemahiran, etika dan kerohanian, serta sahsiah yang positif. Dari segi kemahiran, informan menyatakan bahawa pelajar remaja yang cemerlang perlu memiliki kemahiran berfikir aras tinggi. Selain itu, mereka juga perlu memiliki kemahiran-kemahiran lain seperti kemahiran literasi, kemahiran numerasi, kemahiran bahasa, serta kemahiran insaniah yang meliputi kemahiran komunikasi dan kepimpinan.

Dapatan ini ditunjukkan dalam petikan kata-kata informan seperti berikut:
“...Kemahiran Berfikir KBAT...bijak membuat pertimbangan dan berani melakukan keputusan yang betul...”
“...pelajar perlu menguasai sepenuhnya kemahiran literasi dan numerasi...kemahiran dwibahasa...pelajar perlu mengetahui Bahasa Melayu dan Bahasa Inggeris ... bahasa etnik atau bahasa bangsa sendiri merupakan nilai tambah seseorang pelajar...”
“...kemahiran memimpin...berdaya tahan, kecerdasan, emosi, kemahiran berkomunikasi dengan berkesan yang merangkumi banyak segi, khasnya kepimpinan di sekolah melalui badan kepimpinan, penglibatan pelajar melalui kokurikulum telah memberi peluang kepada pelajar untuk lebih menceburkan diri dan penting untuk masa depan pelajar..."

Dari segi etika, informan menyatakan bahawa pelajar remaja yang cemerlang perlu mempunyai etika dan kerohanian serta memiliki identiti nasional. Dapatan ini ditunjukkan dalam petikan kata-kata informan seperti berikut:

"Etika dan kerohanian ... pelajar menerapkan etika dan kerohanian dalam diri bagi mengharungi cabaran dalam kehidupan, mampu menyelesaikan konflik secara harmoni...identiti nasional...berpegang teguh kepada lima prinsip Rukun Negara ..."

Dari segi sahsiah yang positif, informan menyatakan bahawa pelajar remaja yang cemerlang perlu memiliki sifat bertanggungjawab terhadap pembelajaran mereka dan mempunyai keinginan untuk menimba pengetahuan baharu. Dapatan ini ditunjukkan dalam petikan kata-kata informan seperti berikut:

“...ciri-ciri yang perlu ada ialah bertanggungjawab, tahu peranan sebagai pelajar dan menyiapkan latihan yang diberikan oleh guru ...pelajar menekankan bahawa pembelajaran adalah untuk sepanjang hayat dan sentiasa ingin mengetahui pengetahuan yang baharu..."

\subsection{Cabaran Yang Dihadapi Dalam Proses Pengajaran dan Pembelajaran Pelajar Remaja} Berdasarkan dapatan daripada temubual yang dijalankan, terdapat tiga cabaran yang dihadapi dalam proses pengajaran dan pembelajaran pelajar remaja. Cabaran yang pertama adalah dari segi kesediaan pelajar, di mana menurut informan, tahap kesediaan pelajar mampu mempengaruhi kelancaran proses pengajaran dan pembelajaran.

Dapatan ini ditunjukkan dalam petikan kata-kata informan seperti berikut:

“...cabaran, bagi saya yang paling ketara mesti adalah kesediaan pelajar. Kalau kesediaan pelajar itu memang mencapai tahap yang cukup bersedia itu, mereka pastinya dapat mengikuti sesi P\&P dengan baik. Dan kita perlu menarik minat pelajar terlebih dahulu bagi memastikan PdPc yang berjaya". 
Mohd Razimi Husin, Nurulhuda Md Hassan, Victor Yii Zi Sheng, Alia Syazwani Md Tormiz, Nur Syaiera Amera Zulkapli, Milleny Anak George, Roslina Rosli, Nur Irzwana Rabiatul Adawiyah Mohammad Hishamuddin, Nor Syafiqah Shaharudin, Chelsea Sovency Adampai.

Di samping itu, guru juga menghadapi cabaran dari aspek perkembangan emosi yang dilalui oleh pelajar ketika memasuki peringkat remaja. Dapatan ini ditunjukkan dalam petikan kata-kata informan seperti berikut:

“...cabaran adalah apabila pelajar remaja ini, khasnya, emosi ini kita pun fahamlah. Jadi belasan tahun ini umur 13 hingga 17 or 18, they're in school. Jadi banyak perkara yang akan berlaku dalam the development of their lives..."

Selain daripada aspek kesediaan dan perkembangan emosi pelajar, perubahan kurikulum yang berlaku dalam sistem pendidikan turut memberikan cabaran kepada guru dalam menjalankan proses pengajaran dan pembelajaran pelajar remaja, di mana keadaan ini memberi kesukaran kepada guru dalam aspek penyediaan bahan pembelajaran. Dapatan ini ditunjukkan dalam petikan kata-kata informan seperti berikut:

“...bahan pembelajaran menjadi semakin sukar kerana perlu disesuaikan mengikut tahap perkembangan kognitif remaja dan ekspetasi untuk memperoleh pencapaian akademik yang lebih tinggi. Dan khasnya sekarang, content dalam kita punya silibus, memang semakin mencabar. Kalau kamu ada adik-adik di rumah, kamu boleh tanya merekalah sebab ada yang baru Form 4 dia kena pergi untuk belajar tajuk di Form 6 pula, contohnya. Yang Form 1 akan belajar bab-bab yang dulu-dulu diajar di Form 4 ..."

\subsection{Penggunaan Teknologi Dalam Konteks Pembelajaran Pelajar Remaja}

Dapatan yang diperoleh daripada temubual menunjukkan bahawa informan mengakui keberkesanan penggunaan teknologi dalam meningkatkan pembelajaran pelajar remaja. Secara spesifik, informan menyatakan bahawa penggunaan teknologi membolehkan pelajar mendapatkan maklumat berkaitan pembelajaran selain meningkatkan keberkesanan proses pengajaran dan pembelajaran melalui teknik penyampaian yang menarik.

Dapatan ini ditunjukkan dalam petikan kata-kata informan seperti berikut:

“...tentang penggunaan teknologi dalam kalangan pelajar remaja, for me, it is a very superb in getting information. Merupakan kaedah yang sangat berkesan untuk mendapatkan informasi dan untuk mendalami pengetahuan. Contohnya, kita boleh mendapatkan ebook, buku, artikel, jurnal dan Mr. Google. Mr. Google merupakan rakan kita yang setia, saya rasa...menguasai penggunaan teknologi untuk meningkatkan keberkesanan sesi PdPc melalui teknik penyampaian yang menarik. Jadi saya rasa ini dapat membantulah, dapat membantu untuk meningkatkan pembelajaran pelajar. Jadi penggunaan teknologi ini kalau digunakan dengan sebaik mungkin, dia akan memberi kesan yang positif daripada yang negatif."

\subsection{Keberkesanan Pembelajaran Abad Ke-21 dalam Meningkatkan Keberkesanan Pembelajaran Pelajar Remaja}

Berdasarkan dapatan yang diperoleh daripada temubual yang dijalankan, informan menyatakan bahawa pembelajaran abad ke-21 berkesan dalam meningkatkan pembelajaran pelajar remaja. Ini adalah berdasarkan kepelbagaian kemahiran yang perlu diterapkan dalam kalangan pelajar dalam konteks pembelajaran abad ke-21, selain penekanan terhadap elemen 4C, iaitu communication, critical thinking, collaboration, dan creativity.

Dapatan ini ditunjukkan dalam petikan kata-kata informan seperti berikut:

"Jadi kemahiran pembelajaran dengan inovasi, learning and innovation skills. Yang kedua, kemahiran maklumat, media dan teknologi, information, media and technology skills. Kemahiran hidup dan kerjaya, life and career skills. Dan dalam ciri-ciri pendidikan abad ke-21 ini, menggariskan empat $C$ yang begitu penting bagi saya, communication, komunikasi, critical thinking, pemikiran kritis, problem solving, collaboration, kolaborasi, creativity. Jadi ini saya rasa elemen-elemen ini mampu untuk meningkatkan keberkesanan pembelajaran pelajar pada masa kini.” 
Mohd Razimi Husin, Nurulhuda Md Hassan, Victor Yii Zi Sheng, Alia Syazwani Md Tormiz, Nur Syaiera Amera Zulkapli, Milleny Anak George, Roslina Rosli, Nur Irzwana Rabiatul Adawiyah Mohammad Hishamuddin, Nor Syafiqah Shaharudin, Chelsea Sovency Adampai.

Perspektif Guru Terhadap Pembelajaran Pelajar Remaja.

Journal of Humanities and Social Sciences, vol. 3, no. 1, pp. 40-49, April 2021. DOI: 10.36079/lamintang.jhass-0301.211

\subsection{Peranan Guru Dalam Mewujudkan Persekitaran Pembelajaran Yang Kondusif Bagi Pembelajaran Remaja}

Berdasarkan dapatan yang diperoleh daripada temubual yang dijalankan, terdapat beberapa peranan yang perlu dimainkan oleh guru dalam mewujudkan persekitaran pembelajaran yang kondusif bagi pelajar remaja. Pertama, guru perlu berkolaborasi dan menjalinkan hubungan interpersonal yang baik dengan pelajar dalam memastikan kelancaran proses pengajaran dan pembelajaran yang dijalankan. Selain itu, guru juga perlu menjadi model peranan kepada pelajar.

Dapatan ini ditunjukkan dalam petikan kata-kata informan seperti berikut:

“... kita perlu mendapatkan kerjasama daripada pelajar. Jadi bila ada hubungan dua hala yang sangat berkesan ini, I am sure PdPc akan dapat dijalankan dan mempunyai pertalian yang sangat rapat dengan pelajar...mewujudkan hubungan interpersonal yang baik antara guru dan pelajar. Saya rasa ini merupakan elemen yang sangat penting, that is called personal touch. Personal touch apabila ada satu hubungan yang begitu of course there's a gap between teachers and students, but for me, if we have that kind of relationship, lebih senang untuk kita, mudah untuk berbicara dalam sesi pengajaran dan pembelajaran."

“...guru sebagai role model. I think this one semua orang akan setujulah, sebab guru sebagai role model ini memang, kalau kita sebagai pelajar dahulu memang, 'Oh, this teacher, that teacher...' so yang menjadi role model itu akan menjadi inspirasi kepada pelajarlah..."

\section{Perbincangan dan Kesimpulan}

Dapatan kajian menunjukkan bahawa faktor kesediaan pelajar mempengaruhi pembelajaran pelajar remaja, di mana pelajar perlu memiliki kesediaan kognitif dan emosi sebelum proses pengajaran dan pembelajaran dijalankan. Dapatan ini boleh dijustifikasi dengan mengambilkira kesan kesediaan dalam mempengaruhi keberkesanan proses pengajaran dan pembelajaran. Dalam hukum pembelajaran yang diperkenalkan oleh Thorndike, salah satu aspek yang perlu diberi perhatian ialah kesediaan pelajar, di mana pembelajaran dikatakan akan menjadi lebih berkesan sekiranya pelajar telah bersedia dari segi fizikal, emosi, dan kognitif.

Di samping itu, dapatan kajian turut mendapati bahawa kompetensi yang dimiliki oleh guru turut mempengaruhi pembelajaran pelajar remaja. Dapatan kajian ini adalah selari dengan dapatan kajian yang dijalankan oleh Nurulhuda Md Hassan et al. (2019) serta Anuar Ahmad dan Nelson Jinggan (2015) yang mendapati bahawa guru perlu memiliki kompetensi yang meliputi aspek pengetahuan, kemahiran, dan sahsiah. Dapatan ini boleh dijustifikasi dengan mengambilkira peranan kompetensi dalam meningkatkan pembelajaran pelajar. Sebagai contoh, melalui kemahiran pedagogi yang dimiliki, guru dapat mengenalpasti strategi pengajaran yang terbaik untuk digunakan ketika melaksanakan proses pengajaran dan pembelajaran, di mana keadaan tersebut akan meningkatkan pembelajaran pelajar remaja.

Selain itu, dapatan kajian turut menunjukkan bahawa persekitaran bilik darjah mampu mempengaruhi dan meningkatkan pembelajaran pelajar remaja. Dapatan ini boleh dijustifikasi berdasarkan peranan persekitaran dalam mempengaruhi perkembangan pelajar. Menurut Bronfenbrenner, salah satu sistem persekitaran yang mempengaruhi perkembangan pelajar ialah sistem mikro, iaitu persekitaran yang mempunyai interaksi langsung dengan pelajar. Dalam konteks pelajar, bilik darjah merupakan sistem mikro kepada mereka, di mana mereka menghabiskan masa yang banyak bersama guru dan rakan sebaya mereka.

Dapatan kajian turut menunjukkan bahawa kemudahan dan prasarana sekolah yang kondusif mampu meningkatkan pembelajaran pelajar remaja. Dapatan kajian ini adalah selari dengan dapatan kajian yang dijalankan oleh Ashrof Zainuddin dan Fattinbinti Subri (2017) yang mendapati bahawa keberkesanan pembelajaran pelajar meningkat apabila pihak sekolah menyediakan kemudahan yang lengkap untuk kegunaan pelajar. Penyediaan kemudahan dan prasarana sekolah yang kondusif bertepatan dengan konsep sistem ekso yang diperkenalkan oleh Bronfenbrenner. Dalam hal ini, meskipun pelajar tidak terlibat secara langsung dalam keputusan berkaitan dengan kemudahan dan prasarana sekolah, namun keputusan tersebut turut memberi kesan kepada perkembangan pelajar. Justeru, hal ini adalah bertepatan dengan perspektif yang diberikan oleh informan dalam kajian ini 
Mohd Razimi Husin, Nurulhuda Md Hassan, Victor Yii Zi Sheng, Alia Syazwani Md Tormiz, Nur Syaiera Amera Zulkapli, Milleny Anak George, Roslina

yang menyatakan persekitaran bilik darjah dan kemudahan dan prasarana sekolah yang kondusif sebagai faktor yang mampu mempengaruhi dan meningkatkan pembelajaran pelajar remaja.

Dapatan kajian turut menunjukkan bahawa penggunaan teknologi memberi kesan positif terhadap pembelajaran pelajar remaja. Dapatan kajian ini boleh boleh dijustifikasi dengan mengambilkira peranan teknologi maklumat dan komunikasi (ICT) dalam meningkatkan pembelajaran pelajar. Menurut Khadijah et al. 2014 serta Hasnuddin et al. (2015), penggunaan ICT mampu menjadikan proses pengajaran dan pembelajaran menjadi lebih menarik dan berkesan. Sharifah Nor Puteh dan KamarulAzman (2011) pula berpendapat bahawa penggunaan ICT dalam proses pengajaran dan pembelajaran mewujudkan suasana pembelajaran yang menyeronokkan dan meningkatkan kualiti pengajaran guru, manakala Abu Yazid Abu Bakar (2016) mendapati bahawa penggunaan ICT mempercepat penerimaan murid serta menjana pemikiran murid. Selain itu, dapatan ini boleh dijustifikasi dengan mengambilkira perubahan sosio sejarah yang berlaku, di mana pada hari ini, kepentingan teknologi dalam kehidupan manusia tidak boleh disangkal lagi, di mana kegunaannya meliputi pelbagai aspek termasuk pembelajaran. Hal ini adalah bertepatan dengan konsep sistem krono yang diperkenalkan oleh Bronfenbrenner, di mana perubahan sosio sejarah yang berlaku turut memberi kesan kepada perkembangan pelajar.

Hasil kajian mendapati bahawa guru mengakui keberkesanan pembelajaran abad ke-21 dalam meningkatkan pembelajaran pelajar remaja. Dapatan ini adalah selari dengan dapatan kajian yang dijalankan oleh Ainun Rahmah Iberahim, Zamri Mahamod, Wan Muna Ruzanna Wan Mohammad (2017). Dapatan ini boleh dijustifikasi dengan mengambilkira kepentingan memiliki kemahirankemahiran dalam pembelajaran abad ke-21 seperti kemahiran komunikasi, kemahiran sains dan teknologi, kemahiran berfikir, kemahiran interpersonal, kemahiran intrapersonal, dan kemahiran 3M (membaca, mengira dan menulis) dalam konteks pembelajaran pelajar remaja. Sebagai contoh, kemahiran sains dan teknologi membolehkan pelajar remaja membina kemahiran berfikir secara kritis dan kreatif yang boleh diaplikasi ketika mempelajari sesuatu subjek. Secara tidak langsung, aplikasi kemahiran tersebut dapat meningkatkan pembelajaran pelajar remaja.

Dapatan kajian turut menunjukkan bahawa sekolah yang memberi pengiktirafan dan penghargaan kepada pelajar dan guru mampu meningkatkan pembelajaran pelajar remaja. Selain itu, dapatan kajian turut menunjukkan keperluan untuk guru menjalinkan hubungan interpersonal yang positif dengan pelajar remaja dalam usaha mewujudkan persekitaran pembelajaran yang kondusif. Dapatan ini boleh dijustifikasi dengan mengambilkira aspek keperluan pelajar yang perlu dipenuhi bagi membolehkan mereka belajar dengan lebih baik. Antara keperluan manusia yang diperkenalkan oleh Maslow ialah keperluan kasih sayang dan penghargaan, di mana keperluan-keperluan tersebut boleh dipenuhi dengan mewujudkan hubungan interpersonal antara guru dan pelajar serta memberi pengiktirafan dan penghargaan kepada pelajar yang berjaya baik dari segi kurikulum mahupun kokurikulum. Dalam konteks pelajar, hubungan guru-pelajar yang positif serta pengiktirafan dan penghargaan yang diberikan kepada oleh pihak sekolah menjadikan mereka lebih bermotivasi untuk meningkatkan pembelajaran mereka.

Dapatan kajian turut menunjukkan bahawa pelajar yang cemerlang memiliki kemahiran, etika dan kerohanian, serta sahsiah yang positif. Hal ini adalah selari dengan aspirasi murid seperti yang dinyatakan dalam Pelan Pembangunan Pendidikan Malaysia 2013-2025: Pendidikan Prasekolah hingga Lepas Menengah), di mana antara aspirasi murid yang ingin dicapai termasuklah pengetahuan, kemahiran berfikir, kemahiran memimpin, kemahiran dwibahasa, etika dan kerohanian, serta identiti nasional. Selain itu, dapatan ini turut selari dengan matlamat Falsafah Pendidikan Kebangsaan yang bertujuan untuk melahirkan pelajar yang seimbang dan harmonis dengan merangkumkan aspek perkembangan yang bersifat holistik dari segi jasmani, emosi, rohani, intelek, dan sosial. Melalui matlamat tersebut, pelajar bukan sahaja mampu membina kesejahteraan diri mereka, malah turut berupaya menyumbang kepada keharmonian dan kemakmuran keluarga, masyarakat dan negara.

Berdasarkan dapatan kajian, perubahan emosi remaja serta perubahan dalam kurikulum memberikan cabaran kepada guru dalam melaksanakan proses pengajaran dan pembelajaran remaja. Sebagai implikasi, guru perlu memiliki pengetahuan berkaitan dengan perubahan-perubahan yang berlaku dalam kalangan pelajar remaja kerana peringkat ini merupakan proses peralihan daripada peringkat kanak-kanak yang dicirikan dengan kebergantungan penuh kepada orang dewasa kepada peringkat dewasa yang dicirikan dengan autonomi dalam membuat keputusan (Santrock, 2018). Dari segi perubahan kurikulum, guru disarankan agar menyediakan diri dengan pengetahuan berkaitan dengan kemahiran pedagogi yang bersesuaian dengan tahap perkembangan kognitif pelajar remaja. 
Dalam hal ini, teori perkembangan kognitif yang diperkenalkan oleh Piaget (1954) boleh dijadikan sebagai panduan dalam memilih strategi pengajaran yang bersesuaian dengan tahap perkembangan kognitif pelajar remaja.

Sebagai kesimpulan, kajian ini memberi maklumat yang bermanfaat berkaitan dengan aspek-aspek yang perlu diberi perhatian dalam meningkatkan pembelajaran pelajar, khususnya pelajar remaja. Antara aspek yang diketengahkan termasuklah faktor-faktor yang mempengaruhi pembelajaran pelajar remaja serta peranan yang dimainkan oleh guru dan pihak sekolah dalam meningkatkan pembelajaran pelajar remaja. Walaubagaimanapun, kajian ini terbatas kepada jumlah informan yang kecil. Kajian lanjutan dicadangkan agar melibatkan bilangan informan yang lebih ramai agar maklumat yang lebih komprehensif berkaitan pembelajaran pelajar remaja dapat diperoleh.

\section{Rujukan}

[1] J. W. Santrock, Educational Psychology (Edisi ke-6). New York: McGraw-Hill Education, 2016.

[2] D. H. Schunk, Learning theories: An educational perspective (7th Ed). NJ: Upper Saddle River, Pearson, 2016.

[3] R. Mayer, "Applying the science of learning: Evidence-based principles for the design of multimedia instruction," American Psychologist, vol. 63, no. 8, pp. 757-769, 2008.

[4] Pelan Pembangunan Pendidikan Malaysia 2013-2025, Pendidikan Prasekolah hingga Lepas Menengah, 2013. Putrajaya: Kementerian Pendidikan Malaysia.

[5] A. Bandura, Social foundations of thought and action. NJ: Prentice Hall, Englewood Cliffs, 1986.

[6] R. S. Siegler, "Continuity and change in the field of cognitive development and in the perspective of one cognitive developmentalist," Child Development Perspectives, vol. 10, pp. 128-133, 2016.

[7] A. Grenell and S.M. Carlson, Pretense. Dalam D. Couchenour \& K. Chrisman (Eds.), Encyclopedia of contemporary early childhood education, 2016. CA: Sage Thousand Oaks.

[8] M. Gauvain, Peer contributions to cognitive development, in K. Wentzel \& G. B. Ramani (Eds.), Handbook of social influences in school contexts. New York: Routledge, 2016.

[9] M. H. Ashcraft, and G.A. Radvansky, Cognition (Edisi ke-6). NJ: Pearson, Upper Saddle River, 2016.

[10] R. J. Sternberg, Multiple intelligences in the new age of thinking, in S. Goldstein, D. Princiotta, \& J. Naglieri (Eds.), Handbook of intelligence. New York: Springer, 2016.

[11] J. W. Santrock, Life-Span Development (Edisi ke-17). New York: McGraw-Hill Education, 2016.

[12] J. Piaget, The construction of reality in the child. New York: Basic Books, 1954.

[13] M. S. A. Yusoff, S. Mahpol and M. L. I. H. M. Saad, "Kesediaan pelajar terhadap penggunaan aplikasi Kahoot! Dalam pembelajaran Bahasa Arab," International Online Journal of Language, Communication and Humanities (INSANIAH), vol. 2, no. 2, pp. 35-50, 2019.

[14] A. R. Iberahim, Z. Mahamod and W. M. R. W. Mohamad, "Pembelajaran abad ke-21 dan pengaruhnya terhadap sikap, motivasi dan pencapaian bahasa Melayu pelajar sekolah menengah," Jurnal Pendidikan Bahasa Melayu, vol. 7, no. 2, pp. 77-88, 2017.

[15] N. E. Abu, and K. E. Leong, "Hubungan antara sikap, minat, pengajaran guru dan pengaruh rakan sebaya terhadap pencapaian Matematik Tambahan Tingkatan 4," Jurnal Kurikulum \& Pengajaran Asia Pasifik, vol. 2, no. 1, pp. 1-10, 2014.

[16] Nurulhuda, M. Hassan, Nu. Hassan, Z. Osman, S. M. Yasin, N. Mamat, M. C. Mustafa, C.L. Loy, M. M. Radzi, Hashimah, Hussein, K. Kaaminy, A. R. Razalli, R. Ismail, "Early childhood education educators' competency: a qualitative study," Sci.Int. (Lahore), vol. 31, no. 5, pp. 699702, 2019.

[17] A. Ahmad, and N. Jinggan, "Pengaruh kompetensi kemahiran guru dalam pengajaran terhadap pencapaian akademik pelajar dalam matapelajaran Sejarah," JuKu: Jurnal Kurikulum \& Pengajaran Asia Pasifik, vol. 3, no. 2, pp. 1-11, 2015.

[18] A. Ahmad, S. H. A. Rahman and N. A. T. Abdullah, "Tahap keupayaan pengajaran guru Sejarah dan hubungannya dengan pencapaian murid di sekolah berprestasi rendah," Jurnal Pendidikan Malaysia, 34, 1 53-66, 2009. 
[19] N. Ahmad, and N. M. Hassan, "Relationship between the factors of school climate in primary school students' academic achievement," Sci. Int. (Lahore), vol. 32, no. 2, pp. 143-145, 2020.

[20] S. Maxwell, K.J. Reynolds, E. Lee, E. Subasic and D. Bormhead, "The impact of school climate and school identification on academic achievement: Multilevel modelling with student and teacher data," Frontiers in Psychology, vol. 8, no. 2069, pp. 1-21, 2017.

[21] S. Harinarayanan and G. Pazhanivelu, "Impact of school environment on academic achievement of secondary school students at Vellore Educational District," International Journal of Education, vol. 7, no. 1, pp. 13-19, 2018.

[22] A. Zainuddin and F. Subri "The school facilities towards the improvement of students' academic achievement: Case study — secondary schools in Klang," Journal of Modern Education Review, vol. 7, no. 9), pp. 647-653, 2017.

[23] K. A. Razak, N. T. Othman, M. I. Hamzah and H. Zulkifli, "Information and Communication Technology among Excellent Islamic Education Teachers in Selangor Malaysia," Journal International Education Studies, vol. 7, no. 13, pp. 146-156, 2014.

[24] H. B. A. Rahman, N. B. Zainal and N. A. B. A. Karim, "Keberkesanan penggunaan ICT di dalam pengajaran dan pembelajaran Pendidikan Islam bagi Sekolah Kebangsaan Desa Pandan Kuala Lumpur," in Proceeding International Conference on Information Technology \& Society (of IC-ITS 2015), pp. 238-252, 2015.

[25] S. N. Puteh and K. A. A. Salam, "Tahap Kesediaan Penggunaan ICT dalam Pengajaran Dan Kesannya Terhadap Hasil Kerja dan Tingkah Laku Murid Prasekolah," Jurnal Pendidikan Malaysia, vol. 36, no. 1, pp. 25-34, 2011.

[26] A. Y. A. Bakar, "Digital Classroom: An Innovative Teaching and Learning Technique for Gifted Learners Using ICT,” Journal Creative Education, vol. 7, pp. 55- 61, 2016.

[27] P. K. Murphy, and P. A. Alexander, "A motivated exploration of motivation terminology," Contemporary Educational Psychology, vol. 25, pp. 3-53, 2006. 